hensive oak management strategy could include the following:

- Goals and objectives set forth in the open space or conservation elements of the general plan.

- Specific plans that delineate management practices and agency responsibilities for geographic areas containing oak resources the municipality desires to maintain.

- A tree ordinance that may authorize various management activities and provide for incentives and educational programs to be implemented and enforced by local government agencies (planning department, public works department, and parks and recreation department).

- Tree registry programs that identify single tree specimens, providing historical or cultural significance to the community.

- Standards for developers that require permits for tree removal, replacement amounts for specimens removed, placement of trees on subdivision maps and guidelines for construction around oaks, accompanied by fines imposed on developers violating these regulations.

- Input from oak and natural resource specialists on management issues, including the status of existing oak resources and preferred methods for conserving these resources during and after development.

- Educational programs for schools, community groups, developers and real estate agents.

- Programs facilitating oak regeneration coordinated among planners, developers, real estate agents and local nurseries, where seedlings from the locality and care instructions are available to developers and homeowners.

It is up to each planning agency to decide which combination of tools will best serve its needs by fostering stewardship of natural resources within the community.

J. M. Whittington is an Environmental Planner with Bechtel Environmental, Inc. in San Francisco; W. D. Tietje is Natural Resources Specialist/Central Coast, Depairtment of Forestry and Resource Management, UC Berkeley, and is stationed at UC Cooperative Extension, San Luis Obispo County.

The authors acknowledge Steven French, City and Regional Planning Department, Cal Poly State University, San Luis Obispo, for advice on survey design. We thank Dario Caloss, Institutional Research Department, UC Santa Barbara, and Alan Seigrist, Bechtel National, Inc., San Francisco, for assistance with statistical analyses. We also thank the municipal planning agencies for responding to the survey. This study was supported by the UC IHRMP, Cal Poly State University City and Regional Planning Department, and grant \#87-5 from the Renervable Resources Extension Act (RREA).

\title{
Apple rootstocks evaluated for California
}

\author{
Warren C. Micke $\square$ James T. Yeager $\square$ Paul M. Vossen \\ Richard S. Bethell a John H. Foott $\square$ Ronald H. Tyler
}

The semidwarfing rootstocks $M 106$ and M7a usually brought apple trees into bearing earlier than did domestic seedling, formerly the major rootstock used in California. However, the more dwarfing M26 rootstock did not perform well in these studies.

California's apple industry has historically been located in the north and central coastal areas and in the foothills of the Sierra Nevada Mountains. Climate, soil type and terrain vary among these areas as do irrigation practices. Varieties grown also vary with district. In the past, these varieties were grown mostly on domestic seedling rootstock with the trees trained to an open vase system and planted at 50 to 100 trees per acre.

In the early 1970s, as older orchards were being replaced, many growers began asking about higher density plantings and the possible use of semidwarfing and dwarfing rootstocks. Growers who traveled and saw new developments in apple production in other states and countries became especially interested in planting higher density orchards on semidwarfing rootstocks. The major reason for interest in higher density planting was to obtain production at a younger tree age and thus receive earlier return on investment with smaller, more precocious trees. Other reported advantages of this type of planting were increased orchard efficiency and improved safety by being able to utilize shorter or even no ladders. A program was initiated in 1975 to compare four semidwarfing and dwarfing apple rootstocks with domestic seedling. All trees were trained to a central leader system at higher planting densities (134 to 454 trees per acre) than the typical 50 to 100 trees per acre used at that time.

The five rootstocks compared were domestic seedling, M111, M106, M7a and M26. These are listed in the general order of declining tree size, resulting from the size-controlling tendencies of the rootstocks. Limited early plantings indicated that the very dwarfing $M 9$ rootstock produced too small a tree under conditions in California, so it was not included. 'Topred Delicious' and 'Redspur Delicious' were used as the scion varieties in all plots and 'Golden Delicious' in all but one planting. Local varieties important to a specific growing district were sometimes included.

Five experimental plantings were established in coastal and foothill apple districts. Coastal plantings included two in Sonoma, and one each in Santa Cruz and San Luis Obispo counties; the foothill planting was in El Dorado County. Rootstocks were arranged in a randomized complete block design with five replications and four trees per replication for each variety.

Because of differences in tree size produced by these rootstocks, as well as differences in vigor provided by the several varieties and the specific site, tree spacing varied among locations and treatments (table 1). Tree spacing between rows was coordinated with the grower's planting distance, which ranged between 15 and 18 feet with an average of 16 feet for all of the trials. The in-row spacings varied from 6
TABLE 1. Average spacing and tree density by variety and rootstock for all plantings in this study 'Topred Delicious' 'Golden Delicious'

\begin{tabular}{|lcccc} 
Rootstock & Spacing & Trees/acre & Spacing & Trees/acre \\
\hline Domestic seedling & $16 \times 16$ & 170 & $15 \times 16$ & 182 \\
M111 & $15 \times 16$ & 182 & $14 \times 16$ & 194 \\
M106 & $14 \times 16$ & 194 & $13 \times 16$ & 209 \\
M7a & $11 \times 16$ & 248 & $10 \times 16$ & 272 \\
M26 & $9 \times 16$ & 303 & $8 \times 16$ & 340 \\
\hline
\end{tabular}




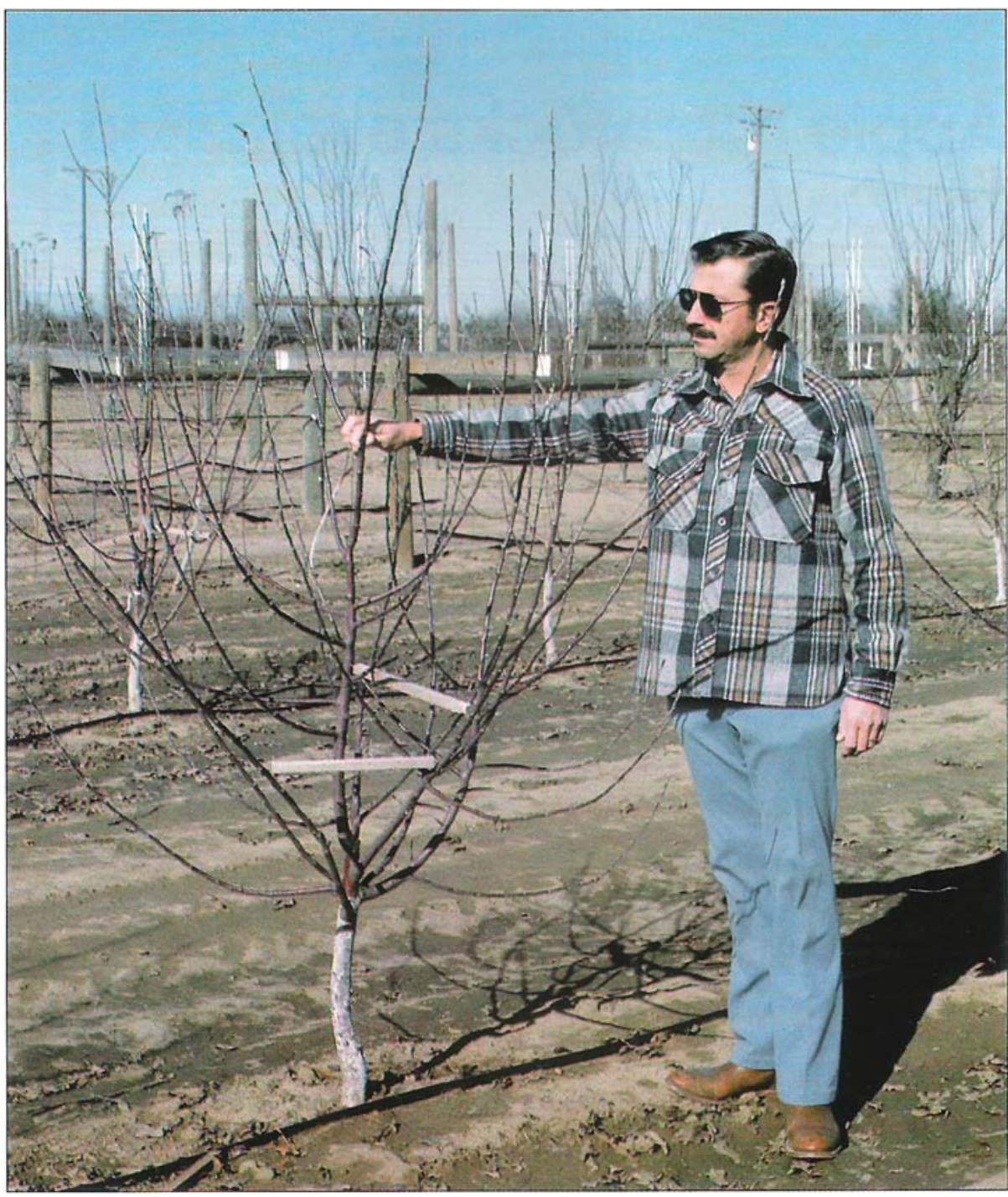

Micke is shown with two-year-old standard 'Red Delicious' on M106 rootstock.

to 18 feet, depending on the anticipated size of the mature trees as affected by rootstock, variety and site.

\section{Early performance}

During the first 2 years, bloom was removed from all treatments to enhance tree development. Irrigation water was applied by either drip or sprinkler, depending on the method used by the cooperator. The amount of water applied varied with district and cooperator practices. From the first season, tree growth of 'Redspur Delicious' on all of the semidwarfing and dwarfing rootstocks at all locations was poor, even with the addition of nitrogen fertilizers and judicious pruning. After 5 years, the decision was made to abandon this spur-type variety due to lack of growth ("runting out") on the size-controlling rootstocks being evaluated.

In 1979-80, heavy rainfall occurred in the north coastal district saturating the soil for prolonged periods and resulting in tree mortality probably due to Phytophthora crown rot. Table 2 lists these tree losses by rootstock for the Sonoma No. 1 (a severe situation) and the Sonoma No. 2 (a less severely affected site) locations. These tree loss results indicated that M111 would not be a good rootstock choice for wet soil conditions in coastal areas. (This apparently does not apply to Central Valley districts where M111 has been used very successfully.) Significant losses also occurred with M26, but these data were not included here because much of this loss could not be attributed to wet soils.

Of the many Phytophthora species, $P$. cactorum was seldom present in coastal soils where these plots were located (although other species were present), which may account for the somewhat better than expected survival of M106. Still, $7 \%$ to $8 \%$ of these trees died at the two locations. In areas where $P$. cactorum is present, trees on M106 rootstock may be more seriously affected. M106 has been reported to be very susceptible to tree loss caused by $P$. cactorum in wet soils.
TABLE 2. Tree losses from wet soil conditions and possible Phytophthora crown rot infection

\begin{tabular}{|c|c|c|}
\hline Rootstock & $\begin{array}{c}\text { Severe } \\
\text { condition, } \\
\text { Sonoma No. } 1\end{array}$ & $\begin{array}{c}\text { Moderate } \\
\text { condition, } \\
\text { Sonoma No. } 2\end{array}$ \\
\hline & \multicolumn{2}{|c|}{........... \% tree loss ........... } \\
\hline Domestic seedling & 15 & 3 \\
\hline M111 & 37 & $\longrightarrow$ \\
\hline M106 & 7 & 8 \\
\hline M7a & - & 0 \\
\hline
\end{tabular}

Most trees in these plantings started bearing during the third growing season. The first 3 years (usually years 3 to 5 in the orchard) of production per tree for both 'Topred Delicious' and 'Golden Delicious' give a good indication of the precocity induced by various rootstocks (table 3 ). However, the trees on the more dwarfing rootstocks would normally be spaced closer; thus, per-acre yields would be proportionally higher than those produced by trees on the more vigorous rootstocks which would need to be spaced farther apart.

With 'Topred Delicious' in both Sonoma County plots, trees on M106 and M7a gave the most early bearing (showed the most precocity) whereas trees on the more vigorous seedling and M111 rootstocks were generally less precocious. In El Dorado County, there was no difference in the precocity induced by any of the rootstocks, and in Santa Cruz County, trees on domestic seedling rootstock unexpectedly produced the highest yields while those on M26 and M106 were the lowest yielding. These data showed that in addition to rootstock, site (including management) had a major influence on early production.

With 'Golden Delicious' trees on M26 often tended to have the lowest production in the early years even though this rootstock is reported to be precocious. Some of this lower production is undoubtedly a result of the smaller tree size provided by M26. With 'Golden Delicious' on other rootstocks, there was little difference in early yields other than in San Luis Obispo County where domestic seedling gave lower production as would be expected based on the performance history of this stock.

\section{Performance of mature trees}

The average yields for mature bearing trees (those over 5 years old) on the various rootstocks are given in table 4 for the Sonoma No. 2 and El Dorado County plots. Due to various circumstances, mature tree yields could not be obtained from. the other three trials. For both 'Golden Delicious' plots and for 'Topred Delicious' in El Dorado County, the yields per tree were 
significantly lower for trees on M26 than for those on the other rootstocks, with no significant differences among the other rootstocks. The 'Topred Delicious' on M106 in the Sonoma No. 2 planting outproduced trees on all other rootstocks, and this variety on M7a yielded significantly more than when planted on M26.

As a point of reference, average tree height for both 'Topred Delicious' and 'Golden Delicious' at the Sonoma No. 2 planting was approximately 10.5 feet for trees on seedling, 10 to 10.5 feet for those on M106, 9 feet for trees on M7a and 6.5 feet for those on M26. For these same varieties in El Dorado County, trees on M111 ranged from 11 to 13 feet tall, those on M106 were 12.5 to 13 feet high and trees on M26 were 10 feet tall.

Based on the actual tree size (spread) from these plots, the proper spacing for central leader trained trees can be calculated and is shown in table 5 for both 'Topred Delicious' and 'Golden Delicious' on various rootstocks under coastal conditions (Sonoma No. 2). At these spacings, trees would have just grown together, but not crowded each other within the row, and there would be a 5- to 6-foot open space (alley) between rows for adequate light penetration into tree canopies as well as for equipment to pass and for fruit to be removed during harvest.

Using the trees per acre for 'Golden Delicious' from table 5 and the average yearly mature tree yield for the Sonoma No. 2 'Golden Delicious' plot in table 4, the calculated production for trees on domestic seedling would be 12 tons/acre ( $t / a c)$, on M106 $14 \mathrm{t} / \mathrm{ac}$, on M7a $15 \mathrm{t} / \mathrm{ac}$, and on M26 $8 \mathrm{t} / \mathrm{ac}$. Although this is an estimate that assumes all other factors remain constant, it does indicate that trees on the semidwarfing M7a and M106 rootstocks were not only more precocious but maintained good production into their full bearing years when planted at the proper spacing. However, when the yields for trees on M26 were adjusted to a proper spacing, the estimated production did not equal that of trees on the other size-controlling rootstocks or even that of those on domestic seedling under the conditions in this particular orchard.

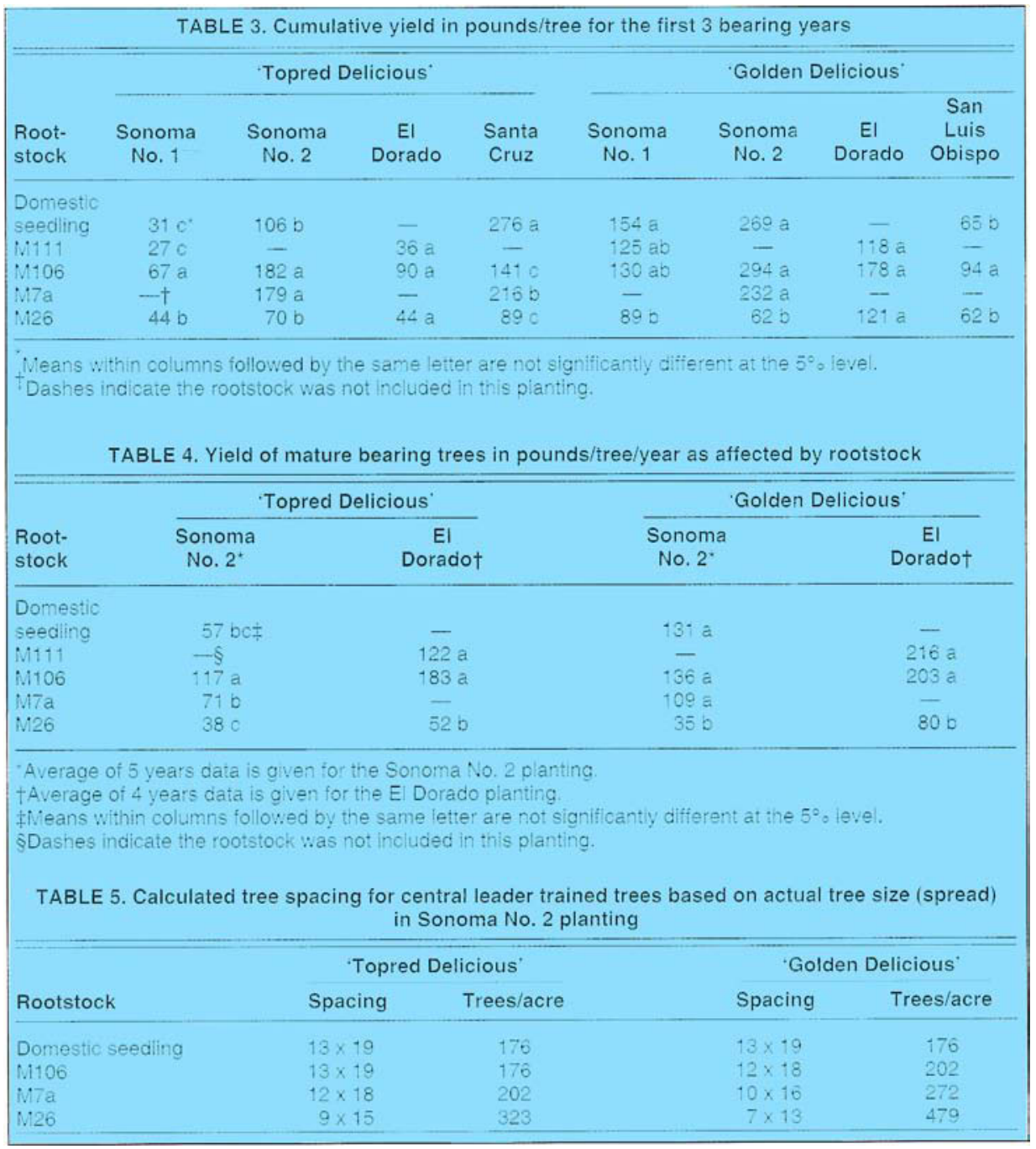

\section{Proper tree care}

To produce a satisfactory orchard, trees on semidwarfing and dwarfing rootstocks require proper culture and care. Their care is more exacting than that required by trees on domestic seedling rootstock in standard orchards. Proper training, pruning, thinning, nutrition and pest control are all important, but the key cultural practice for trees on semidwarfing and dwarfing rootstocks is irrigation. Trees on these rootstocks and particularly M26 will not do well if they are drought-stressed, even for relatively short periods, especially during the first 2 to 3 years of tree development. However, as noted previously, excess irrigation can lead to tree losses.

Once trees on M26 have been waterstressed in their early development, it is difficult and sometimes impossible to get them growing again and maturing into satisfactory trees, even by removing all bloom, giving them extra nitrogen and pruning severely. Such trees, once stunted, tend to remain small without filling their allotted space and often result in an orchard with low production. Based on current knowledge, the trees on M26 in some of these trials may not have been irrigated frequently enough to fully meet their needs; thus, these low yields were obtained.

\section{Conclusions}

The results show that semidwarfing M7a and M106 rootstocks bring trees into bearing more readily than those on domestic seedling and also maintained good production into their mature bearing years. As in many (but certainly not all) commercial plantings in California, the dwarfing M26 rootstock did.not perform well. When planting high-density orchards on size-controlling rootstocks, site selection, tree spacing and proper tree care, especially irrigation, are very important to the success of the orchard. Having some knowledge of any Phytophthora species present and the root rot potential of the site can also be important in determining which rootstock to choose.

W. C. Micke and J.T. Yeager are Extension Pomologist and Staff Research Associate, respectively, Pomology Department, UC Davis. P. M. Vossen, R. S. Bethell, J. H. Foott and R. $H$. Tyler are $U C$ Cooperative Extension Farm Advisors in Sonoma, El Dorado, San Luis Obispo and Santa Cruz counties, respectively.

The authors acknowledge and express their appreciation to John Smith, Farm Advisor Emeritus, and the following growers: Continental Vineyards, Ed Delfino, Mann Orchards, Thomas Marshall and Santa Rosa Junior College. 